\title{
Refraction-seeking behaviour among young people presenting to a medical college hospital of Bihar
}

\author{
Prateek Nishant ${ }^{1}$, Sony Sinha ${ }^{2, *}$, Ranjeet Kumar Sinha ${ }^{3}$ \\ ${ }^{1}$ Former Junior Resident, ${ }^{2}$ Assistant Professor, Dept. of Ophthalmology, Patna Medical College, Bihar, ${ }^{3}$ Associate Professor, \\ Dept. of Community Medicine, Patna Medical College, Bihar, India
}

*Corresponding Author:

Email: nishanteyecare@gmail.com

\begin{abstract}
With an objective to enquire about availability of primary or secondary level facilities for refraction and explore reasons for approaching a tertiary OPD despite awareness of the same, a prospective study was conducted over a two month period in the ophthalmology OPD of a medical college of Bihar among patients aged 10-24 years from Patna district diagnosed with refractive errors, using a predesigned interview schedule and subsequent statistical analysis. Of 1075 subjects, about $61 \%$ of rural young people recalled that refraction facilities (of primary or secondary level) were available in the vicinity of their residence (about $18 \%$ denied availability, and $21 \%$ were unaware) while all 961 urban young people were aware of the same. The prime reason for visit among urban patients was the need for certification from a government institution for admission to an educational institution or job. Hence, there is need to establish new and advertise existing vision centres, conduct community screening, establish government-subsidized optician services network, inculcate importance of counselling patients among all eye care professionals, define the role of a tertiary care institution in the minds of the public and support the tertiary hospital by a high-volume primary eye care facility in the neighbourhood.
\end{abstract}

Keywords: Residence, Refractive errors, Refraction facilities, Screening, Tertiary OPD, Vision centres.

\section{Introduction}

The World Health Organization (WHO) identifies uncorrected refractive errors as a major cause of moderate to severe visual impairment worldwide, amounting to about $43 \%$ of all causes of visual impairment. ${ }^{1}$ The treatment of refractive errors with low-cost spectacles is one of the easier ways to decrease vision problems. ${ }^{2}$

Refractive errors, low vision and childhood blindness are included as three of its seven focus areas of 'Vision 2020: the Right to Sight India'. A publication ${ }^{4}$ by its national secretariat about data from 25 surveillance units indicates that refractive errors are the commonest eye problem for which people consult ophthalmologists. It emphasizes that $80 \%$ of blindness and severe visual impairment is avoidable through comprehensive eye care services and that $80 \%$ of eye problems can be either diagnosed and treated, or diagnosed and referred by adequately trained personnel at the primary level.

India's Vision 2020 strengthens provision of ophthalmic care to the masses through a four-tier organizational structure $^{3}$ to deliver services in the vicinity of those in need of them. It proposes establishment of dedicated vision centres and service centres at peripheral hospitals to carry out screening and correction of refractive errors.

The state of Bihar has a population of about 103.8 million, ${ }^{5}$ about $70 \%$ of which is rural, but its ophthalmological infrastructure in $2013^{6}$ consisted of only 24 vision centres, a ratio of 1:4325000. A large proportion of the population of India in general and Bihar in particular, is comprised of young people (aged
10-24 years ${ }^{7}$ ), a distinctly recognized group mostly of students, whose education, occupation, social and economic security (especially in domains of navy, military, railways and aviation $)^{8,9}$ as well as safety and quality of life ${ }^{10}$ depend upon the eye care services they receive, and they, in turn, affect national productivity. Though indicative of a numerical deficiency of infrastructure and outreach services, available data do not assess the impact of the same on the young people of the state.

The need for this study, in Bihar, was felt as an enquiry has never been made as to why patients prefer to bypass the primary and secondary care institutions where these facilities might be available. The objectives were to enquire about rural or urban residence of young people, the availability of primary or secondary level facilities for refraction in the patients' respective vicinities and explore reasons for their approaching a tertiary OPD despite their awareness of the same. As the utilization of refraction services is just as important as their provision if we are to address the burden of uncorrected refractive errors, ${ }^{11}$ this was expected to serve as an initial enquiry into the 'felt need' of the young people of Bihar for refraction services that will enable hospitals to serve them better by directing efforts to decentralize health care delivery and enabling its optimal utilization by the community at large.

\section{Materials and Methods}

This prospective study was conducted at the OPD of the upgraded Department of Ophthalmology, Patna Medical College (Patna, Bihar, India) among patients aged 10-24 years residing in Patna district in whom a 
refractive error was diagnosed (earlier or now, in one or both eyes) as the study population.

The study was designed to conform to the tenets of Declaration of Helsinki and approved by the Institutional Ethics Committee; accordingly, formal consent notes were presented to patients as per guidelines of Indian Council of Medical Research. ${ }^{12}$ Verbal consent was obtained from those over 18 years of age and from accompanying guardians of patients under 18 years of age as approved by the Ethics Committee.

Data were collected on all working days over a two-month period (Mid-April to Mid-June 2015) using a pre-designed semi-structured interview schedule (Fig. 1) filled up by the investigators, asking them to state as to whether a primary or secondary eye-care centre (as they were made to understand) was available in the vicinity of their residence and the foremost reason why they chose a tertiary care centre for the mere purpose of refractive correction.

Raw data was entered in Microsoft Excel (Microsoft Corporation, USA). Statistical Analyses were performed using SPSS 16.0 for Windows (Statistical Package for the Social Sciences, SPSS Inc., USA).

Responses received were summarized into related thematic areas and presented as frequencies and percentages. The Chi-Square test was employed as test for significance, taking $\mathrm{p}<0.05$ as significant.

\section{Results and Discussion}

At the end of the study period, 1075 young people from Patna district were found to have refractive errors. Of these, $114(10.6 \%)$ belonged to rural and rest 961 (89.4\%) to urban Patna. Thus, there is a gross difference between the number of rural and urban patients. This is probably due to the reason that our facility is situated in an urban area and hence is easily approachable for urban patients. Majority of rural patients were those who were already present in the campus as attendants of other patients from rural areas.

About three-fifths $(61 \%)$ of rural young people recalled that refraction facilities (of primary or secondary level) were, in fact, available in the vicinity of their residence. About $18 \%$ denied their availability, while $21 \%$ were unaware of any such facilities in private or government setups (Table 1). All the 961 urban young people knew of refraction facilities in the vicinity of their residence. This difference was statistically significant $\left(\chi^{2}=395.91, \mathrm{df}=2, \mathrm{p}<0.001\right)$, suggesting either an absolute deficiency, or a lack of awareness of facilities in rural Patna, and that existing facilities in both rural and urban Patna are not providing refraction services to the requirement and satisfaction of young people, compelling them to visit a tertiary centre for the same. As evident by the comparison of these findings with the vision centre to population ratio ${ }^{6}$ of 1:4325000, there is a definite need to establish new and advertise the existing vision centres to motivate people for promptly accessing refractive services should the need arise. Screening in the community is a necessary function of the vision centres, which would cater to the needs of the people quantitatively and qualitatively.

Various reasons enumerated by these patients for not utilizing other facilities are summarized in Fig. 2. The prime reason for most patients $(275,27 \%)$ was need for certification from a government institution for the purpose of obtaining admission to an educational institution or job. Thus, there appears to be a need to clearly define the role of a tertiary institution in the minds of the public as a place for specialty care.

An additional 253 patients $(25 \%)$ reported easier access to the medical college hospital than any other facility. The location of Patna Medical College amid a number of educational institutions and densely populated colonies leads young people to visit it. Although a primary care government hospital exists within urban Patna approximately 8 kilometres from this tertiary centre, but people from those areas were also found coming to it.

Dissatisfaction with old spectacles and consequent discontinuation was reported by 207 urban and 16 rural patients (22\% overall), and the persistence of symptoms made them approach the tertiary hospital. The APEDS ${ }^{13}$ also found that nearly one-third of their subjects discontinued the use of spectacles, either because they felt the prescription was not correct or the spectacles were uncomfortable although the finding was not specific to young people. However, it is known that the magnitude of refractive error does change with time in growing children, and it appears that the dissatisfaction is probably related to insufficient counselling for regular follow-up to prescribe changes in the power of the spectacles as needed.

Patients also reported economical service of the tertiary facility and the expectation of superior standard of care from the "big hospital" to be reasons for approaching it. The above findings may be interpreted as a felt need of the young people for the establishment of a high-volume, economical primary eye care facility with capacity for accurate refraction in the neighbourhood of the tertiary hospital.

The rural patients were mainly those who, as attendants of other patients admitted for tertiary care in the wards of various departments, incidentally remembered their ocular symptoms and reported for refraction (17 patients). This again highlights the need to establish vision centres throughout the state, ensure their optimum utilization and spread awareness to distribute the burden of care appropriately.

The hope of getting government-provided spectacles free of cost at the tertiary hospital was another reason, at a time when the national programme for control of blindness has been providing around six lakh free spectacles to school children all over the 
country. ${ }^{6}$ The state of Bihar reported that from April to August $2015,{ }^{14}$ a total of 55355 schoolchildren were screened of which $689(1.2 \%)$ were diagnosed as having refractive errors. Only 39 of them were provided spectacles under the national programme for control of blindness, all of them from the same rural area (Maner in Patna district). Thus, there appears to be a need to establish a government-subsidized optician services network throughout the state. The provision of affordable spectacles has repeatedly been emphasized to be an essential component of Vision $2020 .{ }^{15}$

The limitation of this study is that it is a hospitalbased study. Further population-based studies would doubtlessly provide greater insight into the problem of underutilization of services. However, the above discussion offers preliminary understanding of how the issue should be approached in order to achieve the goal of vision 2020.

Table 1: Availability of refraction facilities as stated by respondents

\begin{tabular}{|l|c|c|c|c|}
\hline Refraction facilities & Rural Patna (\%) & Urban Patna (\%) & Total & \\
\hline Available & $69(60.5)$ & $961(100.0)$ & $1030(95.8)$ & \multirow{2}{*}{$\chi^{2}=395.91$} \\
\cline { 1 - 4 } Not Available & $21(18.4)$ & $0(0.0)$ & $21(19.5)$ & df=2 \\
\cline { 1 - 4 } Don't know & $24(21.1)$ & $0(0.0)$ & $24(22.3)$ & $\mathrm{p}<0.001$ \\
\hline Total & $114(100.0)$ & $961(100.0)$ & $1075(100.0)$ & \\
\hline
\end{tabular}

\section{Interview Schedule}

1. What is your age?

2. What is your occupation?

3. Where do you work/study presently?

4. Where do you presently reside? Rural / Urban Patna

5. Do you know of any institution or facility which offers refraction or spectacle-prescription services in the vicinity of your residence? Yes / No

6. If answer to (5) is yes, please state:

a) Why did you not avail of the facility provided at your nearby institution?

b) Why did you choose to come to our institution to avail of refraction or spectacle-prescription services?

7. Have you been prescribed spectacles earlier elsewhere?

a) If yes are you using them as prescribed? Yes/No

b) Why did you now choose our facility over the one you had gone to earlier?

Fig. 1: Interview Schedule used in the study

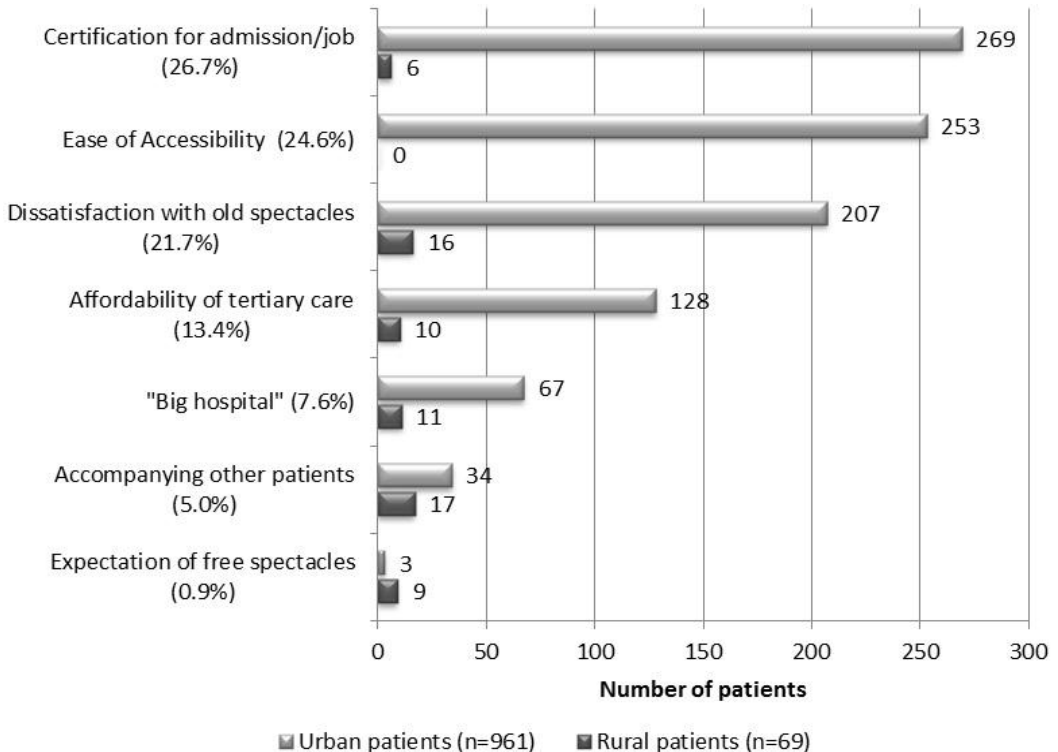

Fig. 2: Reasons reported by patients for not utilizing primary or secondary facilities for refraction ( $\mathbf{N}=1030)$ 


\section{Conclusion}

Our study indicates that there is a definite need to establish new and advertise existing vision centres throughout the state of Bihar to motivate people for promptly accessing refractive services, screen the community, ensure optimum utilization and spread awareness to distribute the burden of care appropriately. Also, there is need to establish a government-subsidized optician services network throughout the state. All eye care professionals ought to counsel patients sufficiently for regular follow-up. Finally, there is need to define the role of a tertiary care institution in the minds of the public and support the tertiary hospital by a highvolume primary eye care facility with capacity for accurate refraction in its neighbourhood.

\section{References}

1. World Health Organization. "Vision impairment and blindness: Fact Sheet," January 2015. Available from http://www.who.int/mediacentre/factsheets/fs282/en.

2. Resnikoff S, Pascolini D, Mariotti SP, Pokharel GP. "Visual impairment in children from refractive error: Estimate of the global prevalence in 2005" Bulletin of WHO (2008) 86(1), $1-13$.

3. Ministry of Health and Family Welfare, Government of India. "National Programme for Control of Blindness," (2004).

4. Vision 2020: the Right to Sight India, Government of India. "Vision Centre Manual, A 'Vision 2020: the Right to Sight India' Publication,” January 2015. Available from http://www.vision2020india.org/pdfs/Vision-CentreManual-2012.pdf.

5. Directorate of Census, Government of India. "Census of India 2011," (2001).

6. Minutes of the annual review meeting of the National Programme for Control of Blindness (NPCB) held on 25th and 26th September, 2013 at Nirman Bhawan, New Delhi, Government of India, August 2015. Available from http://www.npcb.nic.in/writereaddata/mainlinkfile/File303.p df.

7. K Park, Textbook of Preventive and Social Medicine, $22^{\text {nd }}$ Ed (2013), M/S Banarsidas Bhanot (ISBN 9789382219026).

8. Taylor H R, "Refractive errors: Magnitude of the need". Community Eye Health Journal (2000) 13(33):1-2.

9. Lin LLK, Shih F, Hsiao CK, Chen CJ, "Prevalence of Myopia in Taiwanese School Children: 1983 to 2000" Annals of Academy of Medicine (2004) 33:23-336.

10. Vitale S, Cotch MF, Sperduto RD, "Prevalence of Visual Impairment in the United States", Journal of American Medical Association (2006) 295(18):2158-63.

11. Srinivas M, Keeffe JE, Raman U, Rao GN. "Populationbased cross-sectional study of barriers to utilisation of refraction services in South India: Rapid Assessment of Refractive Errors (RARE) Study". British Medical Journal Open (2011) 1(1):e000172.

12. Indian Council of Medical Research, Ethical Guidelines for Biomedical Research on Human Participants (2006)

13. Dandona R, Dandona L, Srinivas M, et al. "Populationbased study of Spectacles Use in Southern India." Indian Journal of Ophthalmology (2002) 50:145-55.

14. Office of the State Programme Officer Bihar, National Board for Control of Blindness, Department of Health, Government of Bihar. "Achievement Report of School Screening in F/Y 2015-2016 under NPCB till August 2015 (Bihar)".
15. Gilbert C, Awan H. "Blindness in children - Half of it is avoidable, and suitable cost effective interventions are available”. British Medical Journal (2003) 327:760-76.

Financial disclosure: Short-term Studentship grant of Indian Council of Medical Research vide ref. no. 2015-04003. 